\title{
JUAN DE PALAFOX Y MENDOZA: REAJUSTES EN SU CAUDAL POÉTICO
}

La poesía del polémico obispo de Puebla fue objeto de publicación póstuma, como la de tantos otros ingenios coetáneos, y ese dato debería despertar en cualquier filólogo cierta cautela, no sólo respecto a la autenticidad de los textos, sino también a su autoría misma. Demasiados estudios y ediciones de nuestros clásicos han admitido datos dudosos, con una fe en la letra impresa que denota ingenuidad, cuando no simple incuria, por parte de quienes prefieren los límites bien marcados: esto pertenece a fulano, esto no, sin términos medios. Desgraciadamente, sin embargo, en la lírica de publicación póstuma las atribuciones imponen su presencia: Garcilaso, Diego de Mendoza, fray Luis de León, Góngora, el conde de Salinas, Quevedo, Villamediana y otros han visto acrecido su peculio en manuscritos e impresos de manera incontrolada, y luego, en el mejor de los casos, han venido las rebajas 1 . Fuera de la literatura castellana lo mismo sucede con poetas como Camões y Petrarca; de éste en concreto se publicó en 1909 un volumen de Rime disperse, que son unas cuarenta, frente a las attribuite, que rebasan las doscientas. Y en la poesía áurea, el día que esté terminada la Bibliografía (BIPA) que tiene en el telar José J. Labrador Herráiz, de la Universidad de Cleveland, con varios colaboradores, se pondrán en claro muchas cosas que están confusas, aunque ello signifique, como dijimos en otra ocasión, dejar confusas otras que ahora pasan plaza de claras indebidamente.

Volvamos a Juan de Palafox y Mendoza, nacido en 1600 y muerto en 1659. Sus obras reunidas comenzaron a publicarse desde ese últi-

${ }^{1}$ A esta cuestión hemos dedicado varios trabajos: "La poesía de Quevedo: textos interpolados, atribuidos y apócrifos", Homenaje a Antonio Vilanova, eds. A. Sotelo y M. C. Carbonell, Universidad, Barcelona, 1989, t. 1, pp. 121-135; "El verdadero autor del Cancionero amoroso atribuido a Pedro de Soria", Manuscrt. CAO, 3 (1990), 17-20; "Nuevos textos y viejas atribuciones en la lírica áurea”, Voz y Letra, 1990, núm. 2, 15-142; "Algo más sobre textos y atribuciones en la lírica áurea", Voz y Letra, 1991, núm. 2, 21-58. 
mo año hasta 1671 en una edición lujosa que consta de nueve volúmenes en folio estampados en distintos talleres. Varios de ellos, como el I, II, IV, anteponen al f. 1 (que puede ir precedido de muchas hojas) un grabado con el retrato del obispo en edad madura; otro distinto figura al frente del tomo IX, que contiene su biografía $^{2}$. Las obras, algunas ya impresas con anterioridad, van apareciendo con sus frontispicios, documentos legales y preliminares. Al llegar al tomo VI escuchamos la voz de fray Joseph de Palafox, que firma la dedicatoria y parece responsable del prólogo, en el cual se dan indicaciones útiles sobre el origen de las poesías:

Este [tomo], a más de las Cartas dichas [las Cartas Doctrinales], sale con unas poesías espirituales del señor Obispo, de que yo no tenía sino noticia: embiómelas vn capellán del Autor, que las iba recogiendo, como él las iba haziendo, y las trasladaua con suma fidelidad, sin que su dueño lo entendiera, que si lo hubiera sabido, no diera lugar a que las pudiéramos gozar: porque su fin solo era vna honesta ocupación en los ratos, que otras mayores le dauan treguas, hazíalas currente calamo, con suma facilidad, y después no las bo[1] uía a ver, dezía lo que la deuoción le dictaua, y ni reparaua en el aliño del romance ni en la repetición de las vozes ${ }^{3}$.

He ahí, por tanto, algo del mayor interés: las poesías de Palafox fueron copiadas a hurtadillas por un capellán del obispo, quien las transmitió al sobrino: "las iba recogiendo, como él las iba haziendo, y las trasladaua con suma fidelidad". Ahora bien, su ilustrísima ¿las iba haciendo o las iba trasladando también él? Eso no lo podía saber el capellán, ni fray Joseph, quien notó la "suma facilidad" con que aparecerían en su escritorio. Al fin, en esa especie de beatitud que produce la buena fe generalizada, todo redundaba en mayor gloria de Dios y edificación de los lectores. Y por otra parte, no cabe duda de que, con facilidad o sin ella, monseñor Palafox escribió bastantes poemas como parte de obras doctrinales: ahí están los 51 Cánticos (pp. 564-689) y los Grados del amor divino (pp. 690-713) para demostrarlo, aunque cuenten, según los estudiosos, con un lastre didáctico que los aleja bastante de la mística o, incluso, de la poesía misma. Lo que es más dudoso es que escribiera poesías sueltas. En semejante situación no resulta nada grato despojar a Palafox de aproximada-

${ }^{2}$ Biblioteca Nacional de Madrid, sign. 2-26.634 / 42 (la signatura que ofrece la Bibliografía de la Literatura Hispánica de J. Simón Díaz está equivocada).

3 (II 2v). La advertencia de fray Joseph al vol. VII en la segunda edición, impresa en 1762, y que difiere bastante de la transcrita, puede verse en Artemio López Quiroz, "Las Varias poesías espirituales de Juan de Palafox y Mendoza: fortuna crítica", apud Juan de Palafox y Mendoza, Poesías espirituales. Antología, ed. y estudios de José Pascual Buxó y Artemio López Quiroz, UNAM, México, 1995, pp. 39-40. 
mente una docena de sus mejores poemas; pero bien se puede asegurar que él, como cualquier ingenio sensato, jamás hubiera aceptado ataviarse con plumas ajenas.

El lector común cuenta hoy con la Antología de poesías espirituales de Palafox citada en la nota 3. Posteriormente, uno de sus editores, José Pascual Buxó, benemérito estudioso de la poesía novohispana, ha publicado un hermoso librito titulado "Habla a los cielos y a los hombres mira": Los sonetos al Calvario de Juan de Palafox y Mendoza 4 , e ilustrado con cuatro grabados de Bernardo Passero para las Adnotationes et Meditationes in Evangelia quae in Sacrosancto Missae Sacrificio... ${ }^{5}$ de Jerónimo Nadal, puesto que, a su juicio, se trata de poesía pictórica: "Los sonetos cristológicos de Palafox parecen tener como punto de partida ciertos pasajes evangélicos presentados en su versión icónica y es a esa ilustración o ekphrasis inversa a la que deben su propia disposición poética y, en buena medida, la transformación de un paratexto bíblico en una creación artística original" (p. 28). Todo ello está muy en su punto, excepto en un detalle: ninguno de los cinco sonetos pertenece a Palafox. Si se atiende a los 29 poemas seleccionados en la Antología, trece, entre ellos esos cinco sonetos, tampoco, y uno más ofrece dudas, como en seguida veremos. Vaya por delante que, de no ser por ambos libros y los entusiastas estudios que contienen, nunca habríamos parado mientes en la obra poética de Palafox, ya que la selección de ella hecha por Alfonso Méndez Plancarte en Poetas novohispanos. Segundo siglo (1621-1721), parte primera ${ }^{6}$, solo incluye un texto de los que podrían hacer saltar la alarma.

Veamos, en primer lugar, cuáles son las poesías sueltas de Palafox, y en qué orden aparecen en el tomo sexto de sus Obras, edición de Madrid: Melchor Alegre, 1667, a costa de la viuda de Juan de Valdés, mercader de libros:

Buela el alma tan alta (canción, pp. 712-713). Finaliza los Grados del Amor divino (pp. 690-713).

Si es bien que la baxeza [no] presuma (soneto, p. 714).

O tú, que del Diuino amor herido (soneto).

Aquella niebla obscura (liras).

Cinco letras tenéis, Diuino Nombre (soneto, p. 715).

Negué atreuido al que ofrecí valiente (soneto).

Mina de aquel diamante, orige $n$ digo (soneto).

Derramado el vngüento (liras de a 6) .

El cielo está confuso, la mar brama (soneto, p. 716).

Que del mundo la máquina se rompa (soneto).

Nace en sagrados braços de alua pura (soneto).

\footnotetext{
${ }^{4}$ UNAM, México, 2000.

${ }^{5}$ Martinus Nutius, Antuerpiae, 1595.

$63^{\mathrm{a}}$ ed., UNAM, México, 1995, pp. 71-93.
} 
O muerto grano que caído en tierra (soneto).

Qué de dudas, Señor, qué de desuelo (soneto).

En santa cárcel, detenidos presos (soneto).

Con mudas lenguas os hablamos claro (soneto, p. 717).

Después que la Virgen vio (glosa en coplas reales).

Recordad, alma dormida (romance).

Pues a los rayos de essa luz diuina (glosa en octavas, p. 718).

En su Concepción María (6 décimas).

Día será de ira y de vengança (tercetos encadenados, pp. 719-720).

La canción "Vuela el alma tan alta" consta de once estancias de trece versos, e ilustra el grado X del Amor divino, lo cual hace más problemático dudar de su autoría. Sin embargo, en versión de solo tres estancias (1, 7 y 10) se copia en el f. 159 del ms. 8273 de la Biblioteca Nacional de Madrid, titulado: Noticia sumaria de el singular don diuino que nuestro Santo Padre fray Juan de la Cruz tuuo para comunicar a las almas contemplatiuas la sabiduría escondida que él auía recebido de el Espiritu Santo. Por el padre fray Joseph de Jesús María, Carmelita descalç, historiador que fue de su orden. Repartida en veynte y dos números. Tras la canción vienen una quintilla y una octava, precedidas de un mote latino:

Buela el alma tan alta

en este extremo passo

al bien eterno, que su amor dispone,

que ya la luz me falta:

porque es este el occaso,

adonde con el sol toda se pone;

ya quiere que corone

con rayos su cabeça:

pues que su luz admite,

y que tanto le imite

en viuos resplandores, y en belleza,

que dudando me admiro,

si es ella el sol, o si en el sol la miro.

Qual el espejo claro,

a los rayos hermosos

del sol, expuesto, al mismo sol imita,

y por el ayre raro

con reflejos vistosos

la luz arroja, que las sombras quita;

tal con otra infinita

el alma resplandeze

con tan viuos colores

de diuinos fauores,

que deificada, el mismo sol pareze:

tan limpia, y christalina, que recibiendo da la luz diuina. 
En el piélago immenso, con venturosa muerte, ganando otra mejor, pierde la vida: porque el amor intenso en otra la conuierte:

[159v] toda queda sumida en el bien que reciue, quando se mira dentro de tan amado centro; $\mathrm{y}$ aquellas aguas con que beue, $\mathrm{y}$ viue de diuinas corrientes, llegando a sus entrañas, forman fuentes.

Ego dormio, \& cor meum vigilat. Cant. 5.

Aquí dormida velando, quando al author de su vida está con su sueño vnida, solo sabe estar gozando, yestar despierta dormida.

$$
* * *
$$

Es vn sueño profundo, y tan despierto, que enagenando al hombre, lo desuela: porque goza durmido, y como muerto, de vn indezible bien, que le reuela el que en soledad le puso, y en desierto; y quanto duerme más, tanto más vela: pues con senzilla mente a Dios mira, que le ilustra, y suspendido admira.

Las variantes de más bulto, como puede verse, están al final de la segunda estancia. Y la var. sumida / en el bien, de la tercera, parece asimismo preferible a la conocida. Los tratados en prosa que preceden a los poemas están, curiosamente, escritos en letra distinta y papel menos viejo. Todo lo cual indica que los poemas fueron agregados más tarde y encuadernados con el conjunto. Una nota fechada en 1679, firmada por Ximénez y Matheo y dirigida a su amigo Ortiz (f. 160v), sirve tan solo de terminus ante quem.

De los sonetos "Si es bien que la bajeza no presuma" y "Oh tú, que del divino amor herido" nada podemos decir. Tampoco de la glosa "Pues a los rayos de esa luz divina", ni de la versión del Dies Irae en tercetos, "Día será de ira y de venganza": el venerable prelado puede disfrutar, de momento, su pacífica posesión. Solo añadiremos, respecto a "Recordad alma dormida", que es, como dice el epígrafe, 
contrafactum a lo divino del romance "Recordad, hermosa Celia", impreso por vez primera en la Flor docena (Zaragoza, 1602), y recogido en el Romancero general de 1604. En cuanto a las coplas reales "Después que la Virgen vio", glosan el mote siguiente:

Sin Cruz no hay gloria, ;oh Madero

Divino!, ni con Cruz llanto

eterno, tampoco hay Santo

sin Cruz, que es el verdadero,

el cual no es sino contrafactum de una quintilla glosada por Lope de Vega en sus Rimas Sacras, f. 60:

Sin Cruz no hay gloria ninguna,

ni con Cruz eterno llanto,

santidad y Cruz es vna,

no ay Cruz que no tenga santo,

ni santo sin Cruz alguna ${ }^{7}$.

De las liras de la transformación "Aquella niebla obscura” ya advierte Buxó que "se hallan transcritas y glosadas en prosa en un Tratado de la transformación del alma en Dios, obra de la carmelita descalza Cecilia del Nacimiento, que data de principios del siglo XvII" (Antología, p. 28), y recuerda que, según A. Méndez Plancarte, una copia de los versos de sor Cecilia se habría encontrado entre los papeles del obispo. Esta hipótesis, como se verá, es mucho más probable que la contraria. Sor Cecilia del Nacimiento y su hermana María de san Alberto fueron objeto de la tesis doctoral de Blanca Alonso Cortés, Dos monjas vallisoletanas poetisas (Valladolid, 1944), de donde extraemos los datos siguientes. Hijas del bachiller Antonio Sobrino, portugués, y de Cecilia Morillas, mujer de rara formación cultural para su tiempo (1539-1590), tuvieron varios hermanos, entre los cuales destaca otro carmelita, fray Diego de San José (1559-1623), autor del Compendio de las solemnes fiestas que en toda España se hicieron en la beatificación de N. B. M. Teresa de Jesús (1615). Cecilia nació en 1570 y tomó el hábito del Carmen en 1587. Estuvo diez años en Calahorra, de cuyo convento fue priora, y regresó a Valladolid en 1612, donde desempeñó varios cargos y se dedicó a escribir hasta su muerte, ocurrida en 1647. Blanca Alonso Cortés, pp. 70-77, enumera y extracta sus obras, conservadas en mss. del Convento de la Concepción del Carmen, de Valladolid. La núm. 6 es el Comentario a las Liras de la transformación del alma en Dios, y la núm. 7, un Segundo comentario a las mismas

7 Viuda de Alonso Martín, Madrid, 1614. Estudia brevemente esta glosa III Yolanda Novo, sin plantearse la autoría del mote (Las Rimas Sacras de Lope de Vega. Disposición y sentido, Universidad, Santiago de Compostela, 1990, p. 185). 
liras (ms. núm. 28). Conviene recordar que, en el fervor carmelitano por la obra de san Juan de la Cruz, también sor María, la hermana de Cecilia, compuso las liras que comienzan "Oh dulce noche oscura", alguna vez atribuidas al santo; otros poemas los dedicó a santa Teresa, a Paulo V, autor de su beatificación, al Monte Carmelo, etc. Blanca Alonso estudia a continuación la obra poética de sor Cecilia, transcribe del autógrafo la Lira de la transformación del alma en Dios (ms. núm. 30), y precisa en nota que "Escribió la M. Cecilia las liras, según su propio testimonio, por los años de 1600. Unos diez años después, por mandato del P. Fray Tomás de Jesús, compuso el primer comentario. El segundo es de 1633" (p. 115, nota). Copia luego unas liras AlEspíritu Santo, otras que traducen la Philomela atribuida a san Buenaventura, una versión del salmo CXIII en cuartetas anisosilábicas, romances y glosas. Pocas dudas quedarán, pues, respecto a la autoría de las Liras de la transformación, que todavía atribuye a san Juan el ms. 2201 BNM, f. 128. Curiosamente, don Manuel Serrano y Sanz las daba como anónimas al transcribirlas del ms. 3766 BNM en su Antología de poetisas líricas ${ }^{8}$ : anónimas sí, pero de pluma femenina ${ }^{9}$.

Las décimas "En su Concepción María" fueron publicadas en las Décimas y glossas en alabança de la Inmaculada Concepción de la Virgen Santissima nuestra Señora, Concebida sin mancha de pecado Original... Recopilados por el padre fray Miguel Auellán, de la Orden del Seráfico Padre San Francisco. Impressas con licencia en Málaga, por Iuan Renè. Y por su original en Seuilla, por Alonso Rodríguez Gamarra, frontero del Ciprés de Martín Cerón. Año de 1615. Es decir, impreso por segunda vez cuando Palafox contaba con quince años. El pliego suelto se encuentra en la British Library (C. 63. b. 27) y en la BN de Madrid (VE 58-71) ${ }^{10}$, ejemplar este que será el visto por Gallardo, Ensayo, I, núm. 300. Del cotejo del pliego con la ed. de Pala-

${ }^{8}$ Madrid, 1915 , t. 1 , pp. $45-48$.

${ }^{9}$ José M. Díaz Cerón, S. J., editor de las Obras completas de Cecilia del NacimienTO O. C. D., Espiritualidad, Madrid, 1971, ha encontrado otras atribuciones: "Estas canciones de la Unión y Transformación del alma con Dios por la tiniebla divina de pura contemplación, como las llama en su $1^{\circ}$ Comentario la M. Cecilia, han sido atribuidas, por diversos manuscritos y obras, a S. Juan de la Cruz, al P. Gracián de la Madre de Dios, a D. Juan de Palafox, Obispo de Osma, y todavía Isabel de Jesús, beata toledana, se las atribuyó a sí misma; más aún, como le dice el P. Antonio a la Madre Cecilia, un Padre Franciscano de la Provincia de San Juan Bautista de Valencia, que tradujo unos «Ejercicios de Vida Espiritual del P. Nicolás Eschío», las puso al principio de ellos sin decir nada" (p. 52).

10 Agradecemos la primera referencia a Ralph DiFranco, profesor en la University of Denver y colaborador de la BIPA. El pliego ha sido descrito por MARía CRUZ García de Enterría, Catálogo de los pliegos poéticos españoles del siglo xVII en el British Museum de Londres, Giardini, Pisa, 1977, p. 69, núm. LXXXII, y en Catálogo de pliegos sueltos poéticos de la Biblioteca Nacional, BN, Madrid, 1998, p. 110, n. 136. 
fox se desprende que el obispo no lo tuvo por modelo, a menos que se haya lanzado a enmendarle la plana. Las seis décimas de que consta el poema presentan las siguientes variantes sustanciales (ponemos en segundo lugar la lectura del pliego suelto): v. 11 herido / vencido. 17 el valor / el sabor. 19 su vida / subida. 21 Con rayos del Sol de Oriente / Con arco y flechas de Oriente. 26 y en el calçado argentado / y en su coturno dorado. 48 sin sombra se vio / sin pecado fue. 50 se vio / estuuo. 56 del Pan / en pan. 57 sabor / algo.

Del soneto "Que del mundo la máquina se rompa" se puede afirmar sin escrúpulo que no pertenece a Palafox, puesto que se copia en un ms. fechado cuando el futuro obispo tenía once años: las Flores de poetas, de Juan Antonio Calderón (o de su hermano Agustín, según R. Marín), ms. dedicado al marqués del Carpio en 1611, que perteneció al duque de Gor y hoy para en la biblioteca de B. March en Palma de Mallorca ${ }^{11}$. En la ed. de J. Quirós de los Ríos y F. Rodríguez Marín, publicada con el falso título de Segunda parte de las Flores de poetas ilustres de España ${ }^{12}$, figura en p. 315, con el núm. 216. En el ms. el soneto se atribuye al padre Martín de Roa, ilustre jesuita cordobés ${ }^{13}$, y los editores no anotan nada al respecto. Se encuentra en el ms. 3358 de la Biblioteca Riccardiana, f. 179, con el epígrafe "Soneto de Spinel a la pasion de $\mathrm{X}^{\circ}$ ", según J. Lara Garrido, quien lo copia de E. Mele y A. Bonilla ${ }^{14}$ para incluirlo en su ed. de Poesías sueltas de Espinel ${ }^{15}$, sin cuestionarse tampoco la autoría. Y en el ms. Archivo de Poesía Española, del licenciado Porras de la Cámara (amigo de Cervantes), f. $249 \mathrm{v}$, se atribuye a otro posible autor, con esta rúbrica: "Soneto del Conde estable a vn Crucifixo"16. El Condestable era el duque de Frías don Juan Fernández de Velasco, muerto en 1613, y a

${ }^{11}$ Nos hemos ocupado de él en "Nuevos textos y viejas atribuciones", cit. en nota 1 , pp. 114-115.

${ }_{12}$ Rasco, Sevilla, 1896.

${ }^{13}$ Nacido en Córdoba en 1563, el P. Martín de Roa ingresó en la orden jesuita en 1594, fue catedrático de Retórica y Escritura en el Colegio de Córdoba, luego rector en los de Jerez de la Frontera, Écija, Sevilla, Málaga y Córdoba. Murió en Montilla en 1637. Ramírez de Arellano, entre las obras del P. Roa, cita un ms., ya mencionado por Nicolás Antonio, de Hymnos et Poemata, que no parece haberse impreso (Ensayo de un Catálogo biográfico de escritores de la provincia y diócesis de Córdoba, Madrid, 1921, t. 1, pp. 543a-549b).

14 "Dos cancioneros españoles", RBAM, 10 (1904), p. 172.

${ }^{15}$ Diputación, Málaga, 1985, p. 113.

${ }_{16}$ Ms. B2504 de la Hispanic Society, núm. V en el Catálogo de Rodríguez Moñino y María Brey. Quevedo colaboró en el ms. Flores de poetas con siete poemas. Aunque ello no es razón suficiente, puesto que el ms. no parece haber circulado y solo llegó a imprimirse en pocos ejemplares a fines del siglo xIx, cabe la posibilidad de que por cualquier vía haya conocido el soneto del P. Roa o del Condestable: buena parte de su poesía religiosa se basa en el mismo concepto de san Ambrosio del que el soneto deriva. Cf. nuestro trabajo "La poesía religiosa de Quevedo: intento de aproximación", en Actas del V Congreso de la AISO, ed. de Ch. Strosetzki, Vervuert, Madrid, 2001, pp. 275-286. 
él lo asigna también el libro que contiene los restantes poemas espirituales mal atribuidos a Palafox: la Historia del monte Celia de Nuestra Señora de la Salceda, de fray Pedro Gonçález de Mendoça, Arçobispo de Granada ${ }^{17}$. El libro, venteado por Rodríguez Marín como importante para la historia de la poesía clásica, fue estudiado ejemplarmente por Joaquín Forradellas, quien transcribe sus poemas y enumera las otras obras de su autor ${ }^{18}$. Fray Pedro González de Mendoza (1571-1639) fue, en efecto, hermano del conde de Salinas, hijos ambos de los duques de Pastrana Ruy Gómez, el amigo de Felipe II, y Ana de Mendoza, la célebre princesa de Éboli. Se hizo franciscano, y muy joven fue nombrado arzobispo de Osma y Granada, hecho al que Góngora dedicó su soneto "Consagróse el seráfico Mendoza”, de 1611 o quizá de un año antes. De allí fue a Zaragoza, en 1616, y finalmente a Sigüenza en $1623^{19}$, de donde se retiró al monasterio por él reparado:

La reforma y mejora que emprendió llevaron aparejadas la reconstrucción y exorno del monasterio, de la iglesia y de los oratorios que jalonaban el trayecto hasta él. En el libro se nos describe cada uno de estos puntos con minuciosidad, siguiendo un itinerario a la vez topográfico y ascético, de acercamiento progresivo a Dios: entrada al monasterio, ermitas diferentes del camino, portería, jardín-cementerio, noviciado, biblioteca, sacristía, templo. Se nos cuenta con detalle cómo era la fábrica, cómo era el adorno, y, además se transcriben los poemas que don fray Pedro, buen humanista, mecenas y amigo de poetas, mandó pintar o grabar en cada uno de estos lugares... Así, el edificio se convierte en una espléndida antología de poesía sacra -noventa y cinco poemas en total, en latín y en castellano ${ }^{20}$.

La obra resultante, impresa en tamaño folio y forma suntuosa, tiene 5 hojas +882 páginas +51 hojas de índices. Va dedicada a la Señora Infanta doña Margarita de Austria, y consta de cuatro libros; el cap. 19 del segundo resume las vidas de los obispos de la diócesis granadina, e incluye retrato de todos ellos, el último de los cuales es el propio fray Pedro (p. 383). Como dice también Forradellas, "de una manera mucho más viva que el catálogo de una biblioteca, nos presenta la estimativa poética de un hombre de la generación de 1580, de buen gusto, amante de las artes, de la literatura, de los libros - recordemos que ordenó la biblioteca de su monasterio y que redactó y mandó imprimir su catálogo. Se nos aclara un poco también de qué

${ }^{17}$ Juan Muñoz, Granada, 1616, p. 596.

18 "Composiciones líricas en la Historia del monte Celia", Filología, 16 (1972), 85-118.

19 Cf. P. B. Gams, Series episcoporum Ecclesiae Catholicae, Karl W. Hiersemann, Leipzig, 1931.

${ }^{20}$ Forradellas, op. cit., p. 89. 
manera, en un hombre de esa época, se ligan poesía y religiosidad, problema que preocupa en más de uno de los poetas barrocos" (pp. 89-90).

Del resto de los poemas sueltos incluidos en el tomo VI de las Obras de Palafox, los nueve siguientes son de Pedro Liñán de Riaza (Villel, Toledo, h. 1557-Madrid, 1607), y se encuentran en la Historia del monte Celia, seguidos de breves comentarios:

Cinco letras tenéis, Diuino nombre, p. 529.

Negué atreuido al que ofrecí valiente, p. 573.

Mina de aquel diamante, origen digo, p. 466.

Derramado el ungüento, p. 496.

El cielo está confuso, la mar brama, p. 596.

O muerto grano que caído en tierra, p. 615.

Qué de dudas, Señor, qué de desuelo, p. 630.

En Sancta cárcel, detenidos presos, p. 663.

Con mudas lenguas os hablamos claro, p. 664.

Pueden verse también en las Poesías de Liñán, ed. de J. F. Randolph ${ }^{21}$, junto con otros igualmente incluidos en el libro de fray Pedro González de Mendoza pero no copiados por Palafox. Y, por último, el soneto "Nace en sagrados braços de Alua pura", p. 605, es del licenciado Bartolomé Ferrer, que colabora en p. 507 con otro ("Descalço imitador, que ya desnudo"). Forradellas aclara que Ferrer era murciano, escribió poemas laudatorios a obras de Cascales y Rodríguez de Ardila, y ganó un premio en la justa a la muerte de la reina doña Margarita de Austria (p. 92).

Queda por tratar una cuestión menuda. La Historia del monte Celia, de González de Mendoza, se imprimió en 1616. A los trece ejemplares localizados por Simón Díaz hay que añadir el usado por Forradellas en la biblioteca de los PP. franciscanos de Santiago de Compostela. Nosotros hemos manejado el que perteneció a Usoz: BNM, U-1002. Ya observó Forradellas que sus censuras y licencias son de fines de 1613: exactamente el privilegio, fechado el 2 de diciembre, y nada menos que cinco aprobaciones eclesiásticas que van desde el 1 de junio al 22 de noviembre. El libro tuvo, pues, una larga gestación, que podemos cifrar aproximadamente entre 1605 y 1615 y no se debe confundir con la reparación del monasterio en sí misma. Los poemas de Liñán, hechos de encargo, son forzosamente anteriores a julio de 1607, fecha de su muerte. El soneto de Góngora "Pender de un leño, traspasado el pecho", compuesto en 1600 según el ms. Chacón, se imprime por primera vez en las Flores de poetas ilustres de Espinosa (1605) para luego figurar en la "Hermita del portal 
de Belén" del convento de la Salceda, junto con un epigrama de fray Alonso Pimentel, y luego en la Historia del monte Celia, p. 540. No hay por qué llevar tan atrás el proyecto del obispo: lo más probable es que haya leído el soneto en las Flores y contase con la venia del poeta para grabarlo 22 .

Antonio Carreira

Madrid

${ }^{22}$ En pruebas de este artículo, y por mediación de nuestra amiga la profesora Beatriz Mariscal, hemos conocido la edición de El Pastor de Nochebuena, de Palafox, hecha por Miguel Zugasti (Pamplona, 2001), quien en su estudio preliminar identifica ya los poemas de Liñán impresos en la Historia del monte Celia como erróneamente atribuidos a Palafox. Suum cuique. 